\title{
BMJ Open Age and gender differential relationship between employment status and body mass index among middle-aged and elderly adults: a cross-sectional study
}

\author{
Jin-Won Noh, ${ }^{1,2}$ Jinseok Kim, ${ }^{3}$ Jumin Park, ${ }^{4}$ In-Hwan Oh, ${ }^{5}$ Young Dae Kwon ${ }^{6}$
}

To cite: Noh J-W, Kim J, Park J, et al. Age and gender differential relationship between employment status and body mass index among middle-aged and elderly adults: a cross-sectional study. BMJ Open 2016;6: e012117. doi:10.1136/ bmjopen-2016-012117

- Prepublication history for this paper is available online. To view these files please visit the journal online (http://dx.doi.org/10.1136/ bmjopen-2016-012117).

Received 1 April 2016 Revised 3 October 2016 Accepted 12 October 2016

CrossMark

For numbered affiliations see end of article.

Correspondence to Dr Young Dae Kwon; snukyd1@naver.com

\section{ABSTRACT}

Objective: To determine the influence of age and gender, respectively, on the association between employment status and body mass index (BMI) in Korean adults using a large, nationally representative sample.

Design: Cross-sectional study.

Setting: South Korea.

Participants: 7228 from fourth wave of the Korean Longitudinal Study of Aging (KLoSA), the survey's short form and year: 'KLoSA 2012'.

Main outcome measures: BMI.

Results: BMI among the employed was higher than among the unemployed for those under 60 . In terms of gender, employed men reported higher BMI than their unemployed counterparts, whereas employed women reported lower BMI than did unemployed women.

Conclusions: Employment status showed varying impacts on obesity by age and gender. Both unemployment at or after 60 , as well as unemployment among women, is associated with increased BMI compared with unemployment among younger individuals or men, respectively.

\section{INTRODUCTION}

Unemployment has been associated with unhealthy weight status, including overweight/ obesity $^{1}{ }^{2}$ or underweight. ${ }^{3}$ Unemployment might influence weight changes in a variety of manners. First, unemployment leads to an overall decrease in physical activity compared with being active in the workforce. For example, prior to unemployment, occupational activity, consisting of both the commute to work and the actual physical activity of work, makes up the largest portion of all daily activities for most adults. Even employees in a sedentary job are more likely to be physically active than the unemployed. ${ }^{45}$ Second, being unemployed is associated with behavioural changes that influence diet. Unemployment leads to decreased consumption of fruits and

\section{Strengths and limitations of this study}

- Nationally representative data were used.

- A series of regression models were computed to examine the relationship between body mass index and employment status as well as potential moderating effects of age and gender on that relationship.

- Owing to the limitation of data sources, including some socioeconomic factors was not possible.

- The causality of relationships cannot be considered because this is cross-sectional study.

vegetables, and increased consumption of unhealthy foods such as snacks and fast food. ${ }^{6}$ Therefore, unemployment might lead to behavioural changes that affect either physical activity, food intake or both, subsequently resulting in weight gain or weight loss.

Several studies supported the association between employment status and body mass index (BMI). Unemployment appears to be significantly associated with a higher prevalence of obesity in comparison to full-time employment in cross-sectional studies. ${ }^{5}$ 7-9 Longitudinal studies also have found that individuals who experience job loss (ie, become unemployed) gained more weight compared with those remaining in employment. ${ }^{2} 1011$ On the other hand, few studies reported that job loss or unemployment was significantly related to lower weight gain and higher weight loss than employment. ${ }^{12}{ }^{13}$ Although these studies offer evidence of a relationship between employment status and BMI, there are still questions about whether unemployment leads to higher BMI. Gender has been hypothesised as a potential confounder of the relationship between employment status and BMI because men and women experience of unemployment in different ways depends on their different work histories, employment opportunities and 
general life experiences. ${ }^{14} 15$ In addition, obesity in older adults is frequently observed because of a loss of the ability to maintain energy balance with increasing age. ${ }^{16}$ Although age-related differences between the working roles of older men and women are important, the association of age and gender around BMI after being unemployed remains unclear. For instance, several studies found that weight gain related to unemployment was greater in women. ${ }^{12} 510$ However, no such associations were observed in men. ${ }^{17}$ Conversely, according to Morris et $a l,{ }^{11}$ there was a significant increase in weight among men aged 40-59 who experienced unemployment over a 5-year follow-up period.

The majority of previous studies examining the influence of age and gender on the relationship between employment status and BMI report mixed results. Furthermore, most studies examining the relationships between employment status and weight change have primarily focused on developed Western countries; in-depth investigations among Asian populations are limited. Therefore, a population-based study of the Korean elderly may be helpful in clarifying the association between employment status and BMI. Additionally, understanding the pattern of BMI in the elderly might provide insight into developing appropriately timed and effective strategies to improve health status in the later years of life. The purpose of this study was to determine the influence of age and gender, respectively, on the association between employment status and BMI in Korean adults using a large, nationally representative sample.

\section{METHODS}

\section{Data and participants}

We used data from the Korean Longitudinal Study of Aging (KLoSA), which was obtained from a public repository (http://survey.keis.or.kr/USBBSGO00N.do? mnucd=OldDwn5). The population of KLoSA participants includes adults aged 45 or older at the time of the first interview. The Korean Labor Institute conducted the KLoSA, funded by the Korean Ministry of Employment and Labor, collecting data every second year starting in 2006. The purpose of KLoSA is to build up the basic data needed to devise effective social and economic policies to address the trends in population ageing process. Data from the fourth wave of the KLoSA, collected in 2012, were used in this study because they were the latest data available at the time of this analysis. There were 7486 participants in wave 4 of the KLoSA, of which 256 did not provide BMI values and 2 did not provide her/his smoking status or education level; the final analysis model used data from 7228 participants. This study was approved by the Institutional Review Board of the Catholic University of Korea (MC14EISI0075) with a waiver for informed consent because the data were obtained from an already public database.
Variables

BMI was used as the outcome variable and was defined as weight in kilograms divided by height in metres squared $\left(\mathrm{kg} / \mathrm{m}^{2}\right)$. The height, weight and employment status ( $0=$ currently not working; $1=$ currently working), and marital status $(0=$ currently not married; $1=$ currently married) were self-reported. Respondents' education level was also self-reported and categorised as 'elementary level or lower', 'middle school graduate', 'high school graduate' and 'college graduate or higher', which was dummy coded in the regression model. Respondents' age was calculated using their birth year and categorised into three age groups: aged 45-59, 6074 and 75 and over.

Factors related to health behaviour affect obesity. Smokers are less likely to be obese than non-smokers. ${ }^{18} 19$ Some studies indicated that smoking status is related to high risks of central obesity, ${ }^{20}$ and ex-smokers are at increased risk of central obesity even though there is no relationship between central obesity and current smoking status. ${ }^{21}$ In the previous literature, drinkers showed more obesity than non-drinkers, and heavier drinkers are more likely to have increased BMI and higher risk of obesity. ${ }^{22} 23$ In Korea, heavy alcohol consumption ( $\geq 30 \mathrm{~g} /$ day) is associated with high blood pressure and high triacylglycerol in men and high fasting blood glucose and high triacylglycerol in women, and is positively associated with an increased risk of central obesity and metabolic syndrome. ${ }^{24}$ Obese people are generally less active than normal weight people. ${ }^{25}$ Exercise improves body composition, physical functioning, cardiovascular risk and cardiorespiratory fitness. ${ }^{26} 27$ Participants' drinking behaviour was assessed by the Korean version of the Alcohol Use Disorder Identification Test (AUDIT-K). The AUDIT was developed by the WHO as a simple method of screening for heavy drinking and as a brief assessment. In the survey, five yes or no questions were used to measure drinking behaviour: 'experience that feel that will should quit drinking', 'experience blamed about drinking habit', 'experience that get angry because of criticism about drinking', 'guilt experience about drinking', and 'experience drinking in the morning'. Cigarette smokers were categorised into three groups: non-smokers, former smokers and current smokers. Non-smokers included people who have never smoked, former smokers included people who smoked earlier, but who have since quit, and current smokers included people who have smoked continuously. In the questionnaire that included regular exercise, the participants were asked questions with yes or no: 'Do you exercise regularly (at least weekly)?'.

\section{Statistical analysis}

Descriptive analyses were conducted to summarise the sample characteristics. A series of regression models were computed to examine the relationship between BMI and employment status as well as potential moderating effects of age and gender on that relationship. In the first regression model, we included only age, gender, 
and employment status and other controls including marital status, education level and other health-related behaviours such as alcohol drinking, smoking and regular exercise. The final regression model included cross-product terms of employment status and age groups and of employment status and gender to test for a potential moderating effect. A model without crossproduct terms of employment status and age group or gender served as a baseline model. Stata V.13.1 (StataCorp LP, College Station, Texas, USA) was used to estimate the analysis models.

\section{RESULTS}

Characteristics of study participants including BMI are summarised in table 1. BMI scores of the 7228 participants included in this analysis ranged from 12.5 to 37.8 with a mean of $23.2(\mathrm{SD}=2.8)$. There were more female participants $(56.6 \%)$ than male participants. About a third of the study population was younger than $60,46 \%$ were between 60 and 75 , and $24 \%$ were older than 75 . Almost $60 \%$ were employed and $77 \%$ were currently married. About $10 \%$ reported college graduate or higher level of education, $28 \%$ and $17 \%$ high school or

\begin{tabular}{lc} 
Table $1 \quad$ Sample characteristics ( $\mathrm{n}=7228)$ & \\
\hline Characteristic & $\mathbf{n}(\%)$ \\
\hline Employment status & \\
$\quad$ Employed & $4318(59.7)$ \\
$\quad$ Unemployed & $2910(40.3)$ \\
Age group, years & \\
$\quad<60$ & $2175(30.1)$ \\
$60-74$ & $3344(46.3)$ \\
$>75$ & $1709(23.6)$ \\
Gender & \\
$\quad$ Male & $3140(43.4)$ \\
Female & $4088(56.6)$ \\
Marital status & \\
$\quad$ Currently married & $5570(77.1)$ \\
$\quad$ Not currently married & $1658(22.9)$ \\
Education level & \\
$\quad$ Elementary school graduate or lower & $3250(45.0)$ \\
Middle school graduate & $1235(17.1)$ \\
High school graduate & $2001(27.7)$ \\
$\quad$ College graduate or higher & $742(10.3)$ \\
Alcohol drinking status & \\
$\quad$ Normal drinker & $4732(65.5)$ \\
Heavy drinker & $2205(30.5)$ \\
$\quad$ Alcohol dependent & $291(4.0)$ \\
Smoking status & \\
$\quad$ Non-smoker & $4950(68.5)$ \\
Former smoker & $1105(15.3)$ \\
$\quad$ Current smoker & $1173(16.2)$ \\
Regular exercise & $2613(36.2)$ \\
$\quad$ Yes & $4615(62.8)$ \\
No & Mean (SD) \\
Body mass index (range 12.5-37.8) & $23.2(2.8)$ \\
\hline
\end{tabular}

middle school graduate, respectively, and $45 \%$ elementary or lower level. In terms of health-related behaviours, $66 \%$ were normal drinkers, $31 \%$ heavy drinkers and $4 \%$ endorsed alcohol dependence. Sixteen per cent were current smokers, $15 \%$ were former smokers and $69 \%$ reported they had never smoked. Also, 36\% reported that they exercised regularly (table 1 ). In terms of weight status, $43 \%$ had normal weight while $1 \%$ were severely obese, $22 \%$ obese, $29 \%$ overweight and 5\% underweight (not reported in the table).

Table 2 summarises the results from the regression model of BMI on employment status and other covariates. After controlling for health-related behaviours such as alcohol consumption and smoking status and other sociodemographic characteristics including marital status and education level, the relationship between BMI and employment status was influenced by respondent age group and gender. In model 1 , the association between BMI and employment status was not significant (B $(\mathrm{SE})=0.09(0.08), \mathrm{p}=0.22)$ when all the age groups and gender groups were considered as a whole. In model 2, in which cross-product terms of unemployment status and age groups and gender were included, the BMI of the unemployed was lower than the employed among men under 60 (B (SE) $=-0.83(0.15), \mathrm{p}<0.001$ ). Further, the strength and the direction of the association between BMI and employment status changed depending on the age groups included (B $(\mathrm{SE})=0.64(0.16)$, $\mathrm{p}<0.001$ for $60-74$ years old group; B (SE) $=0.92(0.24)$, $\mathrm{p}<0.001$ for the 75 and older group; table 2). This moderating effect of age group on the relationship between BMI and unemployment status is illustrated in figure 1 .

Similarly, the relationship between BMI and unemployment status differed by gender $(B \quad(S E)=0.85$ $(0.14), p<0.001)$. Figure 2 illustrates the differential relationship between BMI and unemployment status by respondent gender.

In terms of health-related behaviours, heavy drinkers had higher BMIs than did normal drinkers $(\mathrm{B}(\mathrm{SE})=0.23$ $(0.08), p=0.004)$ whereas no differences were found between normal drinkers and alcohol dependents (B $(\mathrm{SE})=0.13(0.17), \mathrm{p}=0.466)$. Current smokers had lower BMIs than did non-smokers (B (SE) $=-0.42 \quad(0.11)$, $\mathrm{p}<0.001$ ), but BMI scores of former smokers did not vary from those of non-smokers (B $\quad(\mathrm{SE})=-0.16 \quad(0.11)$, $\mathrm{p}=0.163)$. No differences in terms of their BMIs were found between those who exercised regularly and not (B $(\mathrm{SE})=0.11(0.07), \mathrm{p}=0.134)$.

\section{DISCUSSION}

This study investigated the relationship between employment status and obesity among middle-aged and older individuals using nationally representative data from Korea. Results indicate that age and gender modified the effect of unemployment on BMI. In the case of those under 60, the BMI of employed individuals was higher than that of unemployed individuals. Conversely, 
Table 2 Regression model of body mass index on employment status and other covariates $†$

\begin{tabular}{|c|c|c|c|c|c|c|}
\hline \multirow[b]{2}{*}{ Characteristic } & \multicolumn{3}{|l|}{ Model 1} & \multicolumn{3}{|l|}{ Model 2} \\
\hline & $\mathbf{B}$ & SE (B) & $95 \% \mathrm{Cl}$ & $\mathbf{B}$ & SE (B) & $95 \% \mathrm{Cl}$ \\
\hline \multicolumn{7}{|l|}{ Employment status (ref: employed) } \\
\hline $\begin{array}{l}\text { Unemployed } \\
\text { Age (ref: }<60 \text { years) }\end{array}$ & 0.09 & 0.08 & $(-0.06$ to 0.24$)$ & $-0.83^{\star \star \star}$ & 0.15 & $(-1.13$ to -0.52$)$ \\
\hline $60-74$ years & 0.02 & 0.09 & $(-0.14$ to 0.19$)$ & $-0.23^{*}$ & 0.11 & $(-0.45$ to -0.01$)$ \\
\hline $\begin{array}{l}>75 \text { years } \\
\text { Gender (ref: male) }\end{array}$ & $-0.97^{\star \star \star}$ & 0.11 & $(-1.19$ to -0.74$)$ & $-1.47^{\star \star \star}$ & 0.21 & $(-1.88$ to -1.07$)$ \\
\hline $\begin{array}{l}\text { Female } \\
\text { (Employment status }) \times(\text { age group })\end{array}$ & 0.10 & 0.10 & $(-0.10$ to 0.29$)$ & $-0.37^{\star *}$ & 0.13 & $(-0.62$ to -0.12$)$ \\
\hline (Unemployed $) \times(60-74$ years $)$ & - & - & - & $0.64^{\star \star \star}$ & 0.16 & (0.33 to 0.96$)$ \\
\hline $\begin{array}{l}\text { (Unemployed }) \times(>75 \text { years }) \\
\text { (Employment status }) \times(\text { gender })\end{array}$ & - & - & - & $0.92^{\star \star \star}$ & 0.24 & (0.46 to 1.38$)$ \\
\hline (Unemployed $) \times($ female $)$ & - & - & - & $0.85^{\star \star \star}$ & 0.14 & (0.57 to 1.12$)$ \\
\hline
\end{tabular}

among those 60 and older, the BMI of those unemployed was higher than that of the employed. BMI was also modified by gender. Unemployed women reported higher BMI compared with employed women. In contrast, employed men had higher BMI than unemployed men.

This study aims to reveal the relationship between employment status and BMI, considering the effect of gender and age, respectively, in Korea. The relationship between employment status and obesity has been analysed in several studies. ${ }^{28-31}$ The employed showed higher proportion of obesity compared with the unemployed in a Korean adults group. ${ }^{28}$ Similarly, the retirement from strenuous job is highly related to BMI. ${ }^{29}$ Conversely, another study presented that employment was less associated with BMI or non-significant. ${ }^{30}$ Also obesity increases the probability of unemployment. ${ }^{31}$ These complicated relationships could result from the cause of unemployment and the effect of gender. Unemployment could be the result of retirement or lead to further job seeking. It is possible that the health

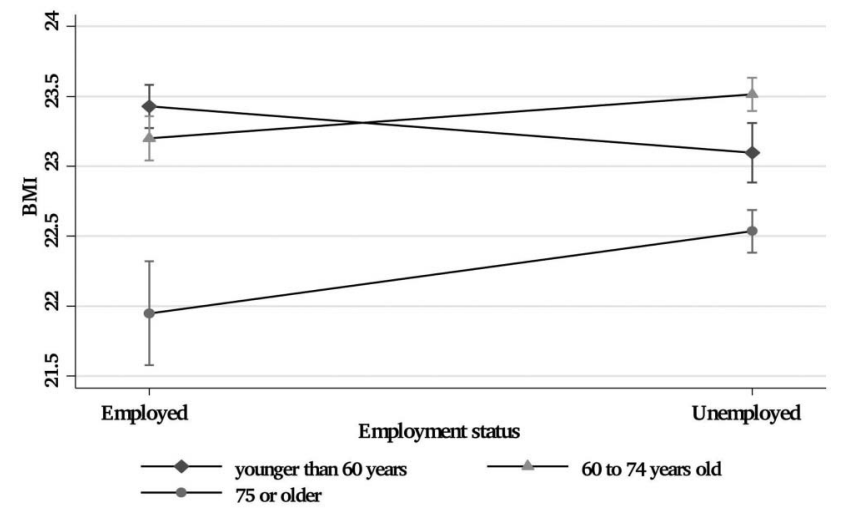

Figure 1 Effect of employment status on BMl by age groups. BMI, body mass index. behaviour of job seekers and retirees could differ. For example, job seekers spend less time participating in sports and are more often smokers, while retirees spend their time on leisure activities. ${ }^{6}{ }^{32}$ Our result also showed that the effect of unemployment differs with age. Among those under 60 years of age, the unemployed were associated with lower BMI compared with the employed. However, among those 60 years and older, the unemployed were associated with higher BMI compared with the employed. When considering that Korea's general retirement age is 60 for men and women, the different pattern between the old age group and the young age group could be affected by retirement. $^{33}$

The effect of retirement on obesity has been on debate also. ${ }^{5-10}$ The calorie expenditure of jobs, food away from home and the psychological effect of retirement were all assumed to be factors that could affect an individual's obesity status. For example, retirement could increase BMI because not working could decrease physical activity. Conversely, retirement could result in a BMI

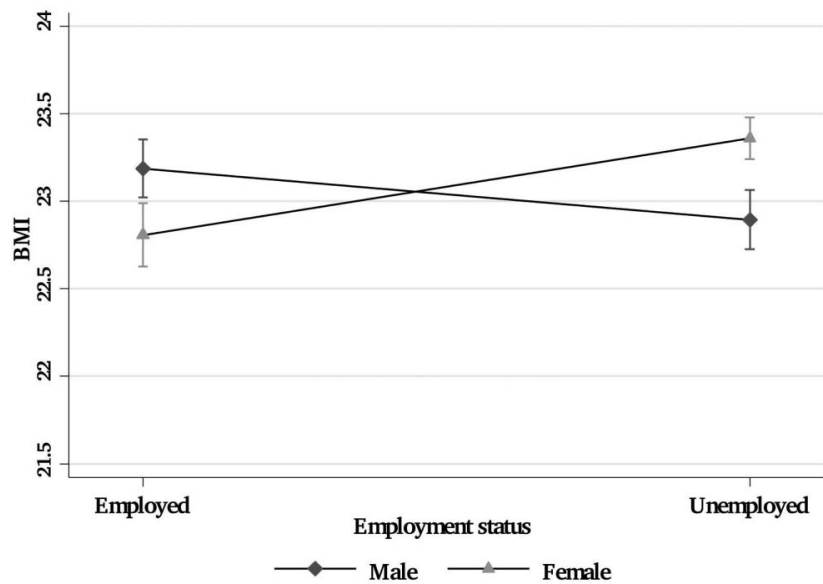

Figure 2 Effect of employment status on BMI by gender. BMI, body mass index. 
decrease through a reduction in eating out. When considering psychological effects, retirement could decrease a sense of belonging, which could cause increase in BMI. ${ }^{5}$ These various findings imply that the effects of retirement on BMI are diverse. For example, Chung and colleagues reported that retirement is associated with an average net gain of $0.24 \mathrm{BMI}$ points, though the effect of ageing overshadowed the effect of retirement. ${ }^{6}$ In contrast, another study reported no association between retirement and BMI among men; in women, however, increased BMI was observed. ${ }^{5}$ Another Korean study observed that among those 65 and older, the OR of obesity in the unemployed compared with those employed full time was 1.451 and 1.399 for men and women, respectively, a significant effect. Among the parttime employees, the OR was observed to be 1.172 and 1.164 for men and women, respectively, though this increase was not statistically significant. ${ }^{7}$

In the case of retirement, Korea is unique. As previously stated, Korea's general retirement age is 60 for men and women. ${ }^{33}$ However, the actual retirement age is closer to 70 years, which is second only to Mexico, and much higher than that of the Organization for Economic Co-operation and Development, which is 63.5. This a result of the high work participation rate of Korea. Among Korean 65-69 years old, more than one half work. Also, like in Mexico and Greece, Korea has a large gender gap in the work participation rate. Therefore, we focused on the impacts of gender and age and the results showed mixed effects. When only BMI, unemployment status, gender and age were considered, no significant relationships were revealed, except age. However, when the cross-product term was considered, unemployment among individuals aged 60 and older, was associated with an increase in BMI. The results of our study are consistent with a previous study, which asserted that unemployment in older age could increase BMI. ${ }^{6}$ A decrease in physical activity could be the reason for this increase in obesity. ${ }^{4}$ In addition, the gender cross-product term showed an increase in BMI among unemployed women. In a previous study on the effect of gender, a similar result that lower socioeconomic status was positively associated with overweight/obesity in Malaysian women and negatively associated in Malaysian men was reported. ${ }^{34}$

However, the results of our study regarding those younger than 60 differ from another cohort study that found that long-term unemployment was related to increasing BMI. ${ }^{8}$ Many Korean companies have allocated money for social gatherings; if workers frequently participate in these alcohol-heavy parties, the calorie intake of those employed could be higher than that of those unemployed. ${ }^{35}$ Further investigation is required to reveal the modifying effect of age on unemployment. Also, this could partially explain the gender difference related to employment status. Generally, alcohol drinking is less tolerated in women in Korean culture; therefore, the calorie impact of alcohol in women could be less than it is for men. ${ }^{36}$ Additionally, the fact that women in the workplace may perceive greater discrimination regarding obesity compared with men could explain the observed gender-based differences in obesity related to employment status. ${ }^{37}$

Among lifestyles, heavy drinkers reported higher BMIs compared with normal drinkers. In the case of alcoholdependent individuals, the gradient is larger, though not large enough to show a significant dose effect. The small number $(4 \%)$ of alcohol dependents may be the reason for this non-significance. The higher BMI among heavy drinkers also implies that alcohol use could contribute to higher BMI in Koreans.

This study has several limitations. First, it did not consider all factors that could affect BMI. For example, socioeconomic factors such as income and education could influence BMI. Additionally, residence or family structure could impact the BMI of older people. Owing to the limitation of data sources, including these factors was not possible. In addition, the nature of employment was not considered in this study. For example, a bluecollar or white-collar job could impact obesity status. Similarly, one's job status, partially employed or fully employed, was not considered, and these factors require further investigation. In addition to that, unemployment status included both unemployed and retired people. Also because BMI does not differentiate fat and muscle, high BMI does not always mean obesity. ${ }^{38}$ Finally, this is cross-sectional study, and therefore the causality of relationships cannot be analysed. For example, high BMI and its related morbidities could hinder an individual's employment status.

In spite of these limitations, this study examines the relationship between employment status and BMI using nationally representative data of Korea, and the interaction effects of age and gender is statistically significant. Unemployment showed different associations with obesity based on age and gender. Considering the differentiating effect of unemployment on obesity, the gender-specific and age-specific obesity intervention for the unemployed would be required.

\section{Author affiliations}

${ }^{1}$ Department of Healthcare Management, Eulji University, Seongnam, Korea

${ }^{2}$ University Medical Centre Groningen, University of Groningen, Groningen, The Netherlands

${ }^{3}$ Department of Social Welfare, Seoul Women's University, Seoul, Korea ${ }^{4}$ National Institutes of Health Clinical Center, Bethesda, Maryland, USA ${ }^{5}$ Department of Preventive Medicine, Kyung Hee University School of Medicine, Seoul, Korea

${ }^{6}$ Department of Humanities and Social Medicine, College of Medicine and Catholic Institute for Healthcare Management, the Catholic University of Korea, Seoul, Korea

Contributors J-WN conceptualised and designed the study, acquired data, drafted the manuscript, critically revised the manuscript for important intellectual content, and approved the final manuscript as submitted. JK conceptualised and designed the study, analysed and interpreted data, drafted the manuscript, critically revised the manuscript for important intellectual content, and approved the final manuscript as submitted. JP and $\mathrm{I}-\mathrm{OH}$ conceptualised and designed the study, critically revised the manuscript for 
important intellectual content, and approved the final manuscript as submitted. YDK conceptualised and designed the study, interpreted data, critically revised the manuscript for important intellectual content, and approved the final manuscript as submitted. All authors read and approved the final manuscript

Funding This research received no grant from any funding agency in the public, commercial or not-for-profit sectors.

Competing interests None declared.

Ethics approval Institutional Review Board of the Catholic University of Korea.

Provenance and peer review Not commissioned; externally peer reviewed.

Data sharing statement Additional data can be accessed via the Dryad data repository at http://datadryad.org/ with the doi:10.5061/dryad.ng8mn.

Open Access This is an Open Access article distributed in accordance with the Creative Commons Attribution Non Commercial (CC BY-NC 4.0) license, which permits others to distribute, remix, adapt, build upon this work noncommercially, and license their derivative works on different terms, provided the original work is properly cited and the use is non-commercial. See: http:// creativecommons.org/licenses/by-nc/4.0/

\section{REFERENCES}

1. Laitinen J, Power $\mathrm{C}$, Ek E et al. Unemployment and obesity among young adults in a northern Finland 1966 birth cohort. Int J Obes Relat Metab Disord 2002;26:1329-38.

2. Monsivais $P$, Martin A, Suhrcke $M$, et al. Job-loss and weight gain in British adults: evidence from two longitudinal studies. Soc Sci Med 2015;143:223-31.

3. Bolton $\mathrm{KL}$, Rodriguez E. Smoking, drinking and body weight after re-employment: does unemployment experience and compensation make a difference? BMC Public Health 2009;9:77.

4. Van Domelen DR, Koster A, Caserotti P, et al. Employment and physical activity in the U.S. Am J Prev Med 2011;41:136-45.

5. Kang HT, Lee HR, Lee YJ, et al. Relationship between employment status and obesity in a Korean elderly population, based on the 2007-2009 Korean National Health and Nutrition Examination Survey (KNHANES). Arch Gerontol Geriatr 2013;57:54-9.

6. Dave DM, Kelly IR. How does the business cycle affect eating habits? Soc Sci Med 2012;74:254-62.

7. Akil L, Ahmad HA. Effects of socioeconomic factors on obesity rates in four southern states and Colorado. Ethn Dis 2011;21:58-62.

8. Schunck R, Rogge BG. Unemployment and its association with health-relevant actions: investigating the role of time perspective with German census data. Int J Public Health 2010;55:271-8.

9. Slack T, Myers CA, Martin CK, et al. The geographic concentration of US adult obesity prevalence and associated social, economic and environmental factors. Obesity (Silver Spring) 2014;22:868-74.

10. Marcus J. Does job loss make you smoke and gain weight? Economica 2014;81:626-48.

11. Morris JK, Cook DG, Shaper AG. Non-employment and changes in smoking, drinking, and body weight. BMJ 1992;304:536-41.

12. Au N, Hauck K, Hollingsworth B. Employment, work hours and weight gain among middle-aged women. Int $J$ Obesity 2013;37:718-24.

13. Montgomery SM, Cook DG, Bartley MJ, et al. Unemployment, cigarette smoking, alcohol consumption and body weight in young British men. Eur J Public Health 1998;8:21-7.

14. Mein $G$, Higgs $P$, Ferrie $J$, et al. Paradigms of retirement: the importance of health and ageing in the Whitehall II study. Soc Sci Med 1998;47:535-45.

15. Kim JE, Moen P. Retirement transitions, gender, and psychological well-being: a life-course, ecological model. J Gerontol B Psychol Sci Soc Sci 2002;57:P212-22
16. Roberts SB, Fuss $\mathrm{P}$, Heyman MB, et al. Control of food intake in older men. JAMA 1994;272:1601-6.

17. Leino-Arjas $P$, Liira J, Mutanen $P$, et al. Predictors and consequences of unemployment among construction workers: prospective cohort study. BMJ 1999;319:600-5.

18. Sund ER, Jones A, Midthjell K. Individual, family, and area predictors of $\mathrm{BMI}$ and $\mathrm{BMI}$ change in an adult Norwegian population: findings from the HUNT study. Soc Sci Med 2010;70:1194-202.

19. Santos R, Aires L, Santos P, et al. Prevalence of overweight and obesity in a Portuguese sample of adults: results from the Azorean physical activity and health study. Am J Hum Biol 2008;20:78-85.

20. Oh SW, Yoon YS, Lee ES, et al. Association between cigarette smoking and metabolic syndrome: the Korea National Health and Nutrition Examination Survey. Diabetes Care 2005;28:2064-6.

21. Xu F, Yin XM, Wang Y. The association between amount of cigarettes smoked and overweight, central obesity among Chinese adults in Nanjing, China. Asia Pac J Clin Nutr 2007;16:240-7.

22. Hou X, Jia W, Bao Y, et al. Risk factors for overweight and obesity, and changes in body mass index of Chinese adults in Shanghai. BMC Public Health 2008;8:389.

23. Lloyd-Richardson EE, Lucero ML, Dibello JR, et al. The relationship between alcohol use, eating habits and weight change in college freshmen. Eat Behav 2008;9:504-8.

24. Yoon YS, Oh SW, Baik HW, et al. Alcohol consumption and the metabolic syndrome in Korean adults: the 1998 Korean National Health and Nutrition Examination Survey. Am J Clin Nutr 2004;80:217-24.

25. Hu G, Barengo NC, Tuomilehto J, et al. Relationship of physical activity and body mass index to the risk of hypertension: a prospective study in Finland. Hypertension 2004;43:25-30.

26. Nelson ME, Rejeski WJ, Blair SN, et al. Physical activity and public health in older adults: recommendation from the American College of Sports Medicine and the American Heart Association. Med Sci Sports Exerc 2007;39:1435-45.

27. Snowling NJ, Hopkins WG. Effects of different modes of exercise training on glucose control and risk factors for complications in type 2 diabetic patients: a meta-analysis. Diabetes Care 2006;29:2518-27.

28. Chang AK, Choi JY. Factors influencing BMI classifications of Korean adults. J Phys Ther Sci 2015;27:1565-70.

29. Godard M. Gaining weight through retirement? Results from the SHARE survey. J Health Econ 2016;45:27-46.

30. Okop KJ, Levitt N, Puoane T. Factors associated with excessive body fat in men and women: cross-sectional data from black South Africans living in a rural community and an urban township. PLOS ONE 2015;10:e0140153.

31. Kinge JM. Body mass index and employment status: a new look. Econ Hum Biol 2016;22:117-25.

32. Freyer-Adam J, Gaertner B, Tobschall S, et al. Health risk factors and self-rated health among job-seekers. BMC Public Health 2011;11:659.

33. OECD. Trends in retirement and in working at older ages. 2011. (accessed 25 May 2015).

34. Sabanayagam C, Shankar A, Saw SM, et al. The association between socioeconomic status and overweight/obesity in a Malay population in Singapore. Asia Pac J Public Health 2009;21:487-96.

35. Lee DS, Park HS, Lee TS, et al. Korean working adults' and undergraduates' attitudes towards, and self-efficacy in, joining drinking parties. Soc Behav Pers 2006;34:487-98.

36. Lee HK, Chou SP, Cho MJ, et al. The prevalence and correlates of alcohol use disorders in the United States and Korea: a cross-national comparative study. Alcohol 2010;44:297-306.

37. Roehling MV, Roehling PV, Pichler S. The relationship between body weight and perceived weight-related employment discrimination: the role of sex and race. $J$ Vocat Behav 2007:71:300-18.

38. Burkhauser RV, Cawley J. Beyond BMI: the value of more accurate measures of fatness and obesity in social science research. $J$ Health Econ 2008;27:519-29. 